\title{
Social organization and control of tuberculosis: the experience of a Brazilian town
}

\author{
Alexandre Favero Bulgarelli ${ }^{1}$ \\ Tereza Cristina Scatena Villa² \\ Ione Carvalho Pinto ${ }^{3}$
}

Objective: this study was aimed at analyzing the participation of a committee formed by representatives of the community in tuberculosis control based on a participatory management model. Method: this is a Case Study involving a tuberculosis committee with data collected through semi-structured interviews conducted with nine individuals. The data, organized through the Association of Ideas Map technique, were analyzed based on the Social Constructionism perspective. Results: the participation of the Tuberculosis Committee studied was shown to be effective and associated with aspects articulated according to the measures taken by the social parties involved in the committee, culminating with assistances inserted into certain parts of the town's co-management. Conclusion: it was concluded that the reality of this case study shows that relationships among civil society can guide the management model in the search for effective processes of tuberculosis control.

Descriptors: Effectiveness; Tuberculosis; Public Health; Social Control, Formal.

\footnotetext{
${ }^{1} \mathrm{PhD}$, Adjunct Professor, Faculdade de Odontologia, Universidade Federal do Rio Grande do Sul, Porto Alegre, RS, Brazil.

${ }^{2}$ PhD, Full Professor, Escola de Enfermagem de Ribeirão Preto, Universidade de São Paulo, WHO Collaborating Centre for Nursing Research Development, Ribeirão Preto, SP, Brazil.

${ }^{3} \mathrm{PhD}$, Associate Professor, Escola de Enfermagem de Ribeirão Preto, Universidade de São Paulo, WHO Collaborating Centre for Nursing Research Development, Ribeirão Preto, SP, Brazil.
} 


\section{Introduction}

In the last few years, the relationship between the civil society and decision making on the part of governments about the development of policies and healthcare measures has strengthened and become recognized as a solid path for the management of healthcare systems in various countries. In this process, the civil society begins to influence the management of public health care ${ }^{(1)}$. In Brazil, the political and institutional design of local bodies, such as local health departments, enables social participation, which is a key instrument in decision making and in the development of public policies that guide the Unified Health System/ SUS. In this context, social groups emerge to support the measures and movements in favor of lines of awareness and development of alternatives to the dynamic social demands and status of diseases (2).

The participation of the organized civil society can minimize the differences and the power dynamics between government and users of public healthcare services. In a sense, the civil society represents certain autonomy of people to participate in the management of health care systems, as well as in the provision of services and measures for disease control(1).

Concerning tuberculosis control, the civil society organizations are increasingly being consulted by institutions and organizations about the ways to approach the populations for health education and control of vaccination, among other measures(3). Based on this fact, the organized civil society somehow becomes an active participant in decision making and is seen as a provider of information for interventions in tuberculosis control(3).

The participation of the civil society in the control of tuberculosis reflects micropolitical contexts of interaction between civilians and the government. In other words, the control of tuberculosis has an important ally, which is the society itself and which, while actively participating in levels of micropolitical negotiations, makes its parties to have credibility to decide and legitimacy to work towards the control of the mentioned disease ${ }^{(1)}$.

In the scope of public health, the joint development of measures for the control of diseases like tuberculosis makes social participation occur through social and dialogical relationships among the people engaged in this control, such as nursing professionals. In Brazil, these relationships, which are relevant for social participation, can happen between managers, users, workers at SUS, and researchers in the areas of negotiation and decision making concerning disease control measures. From this perspective, a group of people working towards collective measures with the purpose of controlling diseases and promoting health to the population can be organized in the form of an instrument of negotiation, decision making and administration, structured as a committee. For such, the control of infectious diseases confirms the need for permanent decision making and negotiations about various situations resulting from the confrontation with this process ${ }^{(4)}$. This is a continuous process, in which a participatory society is required.

The relationship between social participation and tuberculosis control is not substantially addressed in scientific literature. In a sense, there is currently a lack of scientific knowledge concerning the effective participation of organized social groups with the aim of discussing and guiding measures for tuberculosis

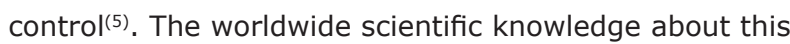
research topic is rare and studies about partnerships between Non-Governmental Organizations/ONG and public health systems are not found in scientific literature ${ }^{(5)}$. Therefore, new experiences of this social participation are required to support the development of knowledge about this construct.

This research is necessary because it may permit the development of further awareness about the participation of civil society in management areas, where public healthcare workers and users jointly contribute towards the effective control of tuberculosis and/or other infectious diseases. Thus, the aim of this research is to analyze a committee performing its social participation in tuberculosis control within the healthcare co-management model in the town of Ribeirao Preto/SP.

\section{Methods}

This qualitative Case Study(6) was theoretically based on the Social Constructionism perspective ${ }^{(7)}$ and guided by the research question: are the possible meanings of the participation of the organized civil society, in the control of tuberculosis, associated with the management model of the town? The object of research is, therefore, the participation of organized civil society representatives on a committee for the control of a concerning infectious disease in the town of Ribeirao Preto/SP. The tuberculosis committee, chosen as the subject of the present research, has an administrative deliberative nature in relation to the measures and programs for tuberculosis control in the town of Ribeirao Preto/SP. 
The town of Ribeirao Preto/SP is the research scenario. The town in question is a national reference for measures involving the development of scientific knowledge and the technical competence in the control of tuberculosis. Such fact plays an important role in supporting the feasibility of the measures with positive results in the control of infectious diseases. The town is provided with the effective work of the tuberculosis committee, which is linked with the local health department.

Since its formation in the 1990's, the mentioned committee, subject of the Case Study, has been dynamically acting for the improvement of the healthcare services in controlling the disease in the town ${ }^{(8)}$. The Committee was formed by an initiative of healthcare professionals - doctors and nurses - as well as university professors and members of the local health department, who established themselves in a place granted by the department itself for the development of an acting group for the control of tuberculosis in the town. The initial reasons that supported the formation of the committee were related to activities to fight other infectious diseases, such as AIDS, and to the concern with the disease indicators in the town and the region which, in a sense, reflected a severe public health issue. Over time, this committee was being structured and obtaining representation at the city health council and is currently a point of reference in the mentioned council, participating in decisions about the measures for the disease control.

The study was designed in four stages ${ }^{(6)}$. In the first stage, the case subject was chosen. Such choice was based on the object and guiding question of the research, because the existence of a specific committee for the control of tuberculosis in the town where the research was developed characterized the subject-case chosen. In other words, following the criteria of particularity and relevance of the subject-case to be chosen, the tuberculosis committee of Ribeirao Preto was chosen, since it is characterized by being a unique subjectcase that contributes to society with its pro activity in decision making and measures of social participation in the control of infectious diseases. The mentioned tuberculosis committee was chosen because it has a historically developed space within the management of the town that allows it to have an active voice, administrative and political powers in decision making concerning public measures for tuberculosis control.

The second stage consisted of data collection. The data were collected during May, June and July 2011, through semi-structured interviews conducted with nine members of the Tuberculosis Committee. The sample of the study was obtained using the snowball technique (snowball sample)(9). Data collection began with the interview of a Nurse who works in SUS, and ended with the interview of a member of the city council and of the mentioned committee. Among the research participants, four were nurses working in SUS and engaged in health surveillance and infectious disease control programs of the local health department, one was a university professor in the healthcare area, one a post graduate student in the healthcare area, one a representative of SUS users, one a member of the city council and one a member of an NGO focused on the control of infectious diseases. The interviews were recorded and transcribed by means of specific rules ${ }^{(10)}$. Figure 1 presents the sample construction process, in conjunction with the categorization of the statements' meanings process throughout the analysis process (Figure 1).

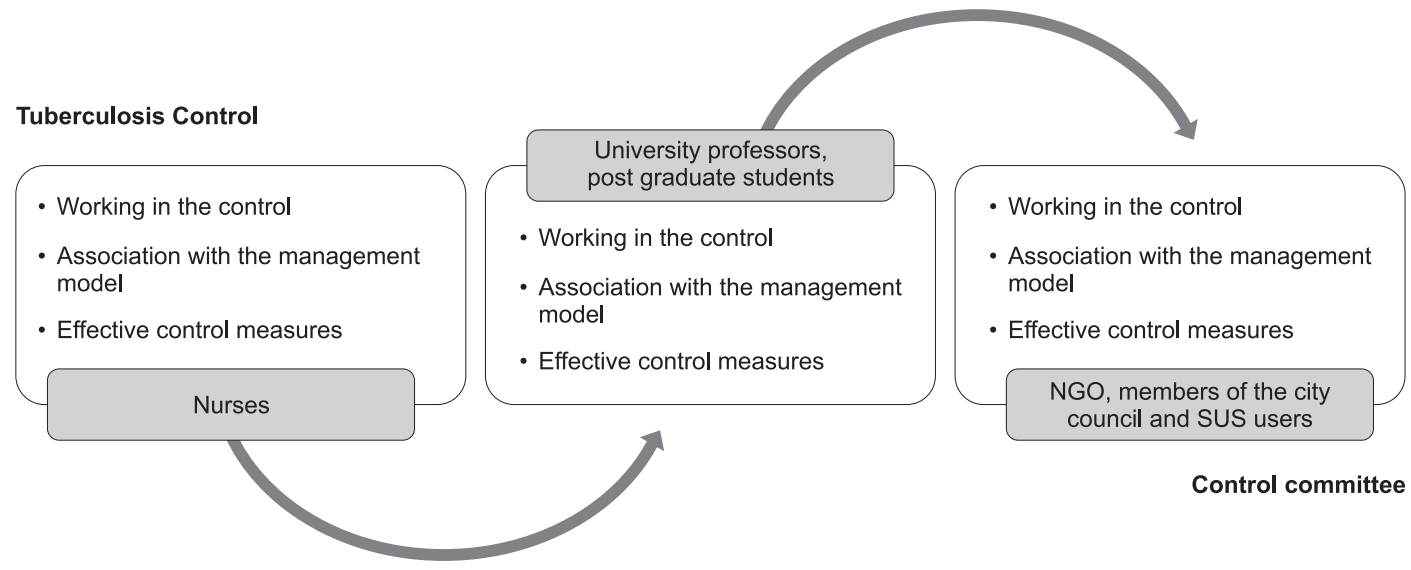

Figure 1 - Illustrative structure of the construction process of the studied sample and categories for analysis. Members of the tuberculosis committee. Ribeirao Preto, SP, Brazil, 2012 
The third stage consisted of the selection, systematization, analysis and interpretation of the data. This was a period of exhaustive reading of the interview transcripts, which permitted the development of analysis categories for further development of Association of Ideas Maps ${ }^{(11)}$. Such maps are resources for the visualization and systematization of data to support the interpretation process of the categories based on the theoretical support chosen(7). Operationally, the maps present the transcripts of the interviews in a continuous form into categories, without changing the sequence of their contents (Figure 2).

\begin{tabular}{|c|c|c|}
\hline \multicolumn{3}{|c|}{ Mapping of the statements in three categories of analysis } \\
\hline 1) Working in tuberculosis control & 2) Effective measures in tuberculosis control & 3) Association with the management model \\
\hline \multirow[t]{2}{*}{$\begin{array}{l}\text {...we have several programs in relation to } \\
\text { infectious diseases... the closest one to the } \\
\text { tuberculosis is the work with AIDS program... } \\
\text { since } 1996\end{array}$} & $\begin{array}{l}{[\ldots] \text { working in the care... in the assistance }} \\
\text { of co-infected people }[\ldots] \text { we seek to provide } \\
\text { assistance to people co-infected with AIDS and } \\
\text { tuberculosis }\end{array}$ & \\
\hline & $\begin{array}{l}\text {...other programs follow the AIDS program... } \\
\text { with all the achievements of these programs } \\
\text { comes the fight against tuberculosis... [...] }\end{array}$ & $\begin{array}{l}\text { concerning the tuberculosis case... what is the } \\
\text { demand? what are the difficulties? what are the } \\
\text { needs? Cases with convicts? Homeless people? } \\
\text { and so forth }[\ldots]\end{array}$ \\
\hline \multirow[t]{2}{*}{$\begin{array}{l}\text { active search is very effective... }[\ldots] \text { some } \\
\text { users used to abandon and did not adhere to } \\
\text { treatment... [...] we have a partnership with the } \\
\text { service... }\end{array}$} & $\begin{array}{l}\text {...the professional nursing activity is very } \\
\text { committed with the search for positive results } \\
\text { concerning tuberculosis... }\end{array}$ & \\
\hline & & $\begin{array}{l}\text {... participation in the council... acting to find } \\
\text { solutions for the problems... it is more effective } \\
\text { today... [...] a real leading role... this is what is } \\
\text { expected...[...] but I still see all this difficulty... }\end{array}$ \\
\hline $\begin{array}{l}{[\ldots] \text { family health strategy... it is the strategy }} \\
\text { that looks after this... the committee enables } \\
\text { healthcare agents to perform this kind of } \\
\text { search... of orientation... of care with the family } \\
\text { of the person with tuberculosis... }\end{array}$ & & \\
\hline
\end{tabular}

Figure 2 - Tuberculosis committee's Association of Ideas Map. Healthcare professionals, representative of an NGO, SUS user and member of the city council. Ribeirao Preto, SP, Brazil, 2012

Association of Ideas Maps are structures built by cutting and organizing the research material, guided by ideas expressed in the form of: performances, metaphors and linguistic expressions(11). From the perspective of this process, the results categorized into ideas/themes and mapped according to the inference of the authors were justified and interpreted with theoretical support from Social Constructionism ${ }^{(7)}$. Social Constructionism is a theoretical perspective that justifies the construction of social realities in the dialogue among various social statements legitimized in the interpersonal conversations, as well as the historical contexts and language of the research object under analysis ${ }^{(7)}$.

The fourth stage consisted of the drafting of a report, presenting and discussing the results in relation to the literature and the perception of the authors, guided by Social Constructionism. The referred stage is embodied in this article.

This study falls into the minimum risk type of research and, according to the Resolution 196/96 of the National Health Council, its approval by the Research Ethics Committee of Ribeirao Preto Nursing College was required. It should be noted that the freedom of the participants of this research was an imperative aspect for their participation in the research and the agreement to participate was established through the signature of the Informed Consent Form.

\section{Results and Discussion}

Parts of the statements of the interviewed participants are presented throughout this article and are inserted into various Association of Ideas Maps, which were developed for analysis. Due to editorial limitations, only one map was presented, showing the categories of analysis that reflect the given meanings and are built through the analysis of the statements of the said committee members (Figure 1 ). The meanings are built through the proximity of interpretation of the statements' central ideas. These meanings, expressed in lines of analysis from the perspective of Social Constructionism $^{(7)}$, were built with the dialogical process of understanding the meanings and were named: Working in tuberculosis control; Effective measures 
in tuberculosis control; and Association with the management model.

The role of the tuberculosis committee of Ribeirao Preto/SP is to think collectively and build jointly, through frequent meetings and distribution of responsibilities and tasks within its members, various ways of controlling tuberculosis in the town. Such ways of controlling the disease are reflections of care measures designed, planned, organized and performed by the committee, such as: training of professionals for diagnosis, sample collection, vaccination campaigns and active search for infected people, supervised treatment, development of scientific research objects, etc.

Within a political context, the tuberculosis Committee was constituted at a time of national fight against infectious diseases and within a legal framework, which is Statute 8,142 of 1988 . The committee was structured in the beginning of the consolidation of SUS and the consolidation of the need for the society to participate in the healthcare of the Brazilian population. Therefore, it is important to emphasize that this was a period of transition from a curative and hospital centered perspective to a health surveillance perspective.

In this historical and political framework, the first line of analysis, named Working in Tuberculosis control, translates the tuberculosis control measures performed by the committee. These measures range from the development of knowledge about the disease activity in the town to specific measures of active search of cases and tracking of infected people. Different strategies for the active search and identification of respiratory symptoms in Primary Healthcare Units should be adopted and this scientific evidence shows the relevance of this aspect of tuberculosis control in regions where the healthcare units are located(12).

Social constructionism can contribute to the understanding that many healthcare actions are developed by dialogical contexts among various parties, because the dialogue leads to the construction of knowledge $\mathrm{e}^{(13)}$. This can lead to the understanding that healthcare actions aimed at controlling diseases can arise within a dialogical context, addressing cases of vulnerability of the city population in combination with problem-solving ability issues of committee actions. Therefore, it can be highlighted: [...] we, from the organized civil society [...] we may not do it directly but we do it indirectly [...] because we discuss [...] we propose guidelines when: [...] this year, we organized training with the primary healthcare units directed at nurses and nursing professionals [...] (Participant 1, Nurse working in SUS).
The search for solutions to cope with the disease in the city is shown as a guiding framework for measures of training professionals to act as watchmen. The person directly responsible for the identification and notification of cases is often the professional who directly deals with the clinical treatments. One of the committee's activities is to organize training for the continuous qualification of healthcare professionals. The committee, articulating from the discursive perspective, addresses technical issues that will influence the disease control. This articulation is shown to be, within a social constructionism perspective, a link of knowledge construction that is based on the social space, where interactions take place, such as the conversational space of the committee(7).

Within the social constructionism perspective, for the construction of something, the conversational space is based on the conversation among people ${ }^{(7-11)}$ and exists between the organized civil society and the local health department, with the committee as a partner, as a postmodern example of development of healthcare measures ${ }^{(7)}$. The term postmodern is related to the current social scenario in which the measures and constructions also happen within a collective conversational perspective, where several parties communicate and build something collectively.

From this perspective of understanding the reality, the presence of different social areas, jointly acting in a public and collective institution and having a common goal, offers pro-active contributions at a micropolitical level in the context of the town's epidemiological reality. Therefore, proposing guidelines relates to directly participating in the development of policies and indirectly in the population's health. Confirming this fact, the tuberculosis committee of Ribeirao Preto contributes, as a co-manager, with several measures concerning the active search for cases, staff training and population awareness.

The tuberculosis committee, in its activities, is similar to the perspective of the co-management model noted in the literature, because it provides a space for the development and compatibility of demands and projects $^{(4-14)}$.

The search for equity in healthcare actions, aimed at reaching vulnerable populations, such as homeless people (Figure 2), provides strong evidence that social partnerships are essential when it comes to controlling diseases affecting heterogeneous populations ${ }^{(15)}$. The work developed by this tuberculosis committee, as per the literature, is shown to have an integrative role, always 
in the attempt to articulate what the decentralization of power often tends to oppose or divide(4).

The partnerships between civil society and healthcare services are shown to be essential in controlling endemic diseases. From this partnership relationship, the development of management practices, the convergence of common interests, the strengthening of information systems, as well as the continuous strengthening of people involved in the partnerships emerge ${ }^{(16)}$.

It is important to highlight that the relationships built, which guide the measures taken within a discursive perspective to develop something through subjective inter-relations, make the effects of a successful partnership always trigger positive results. This aspect confirms the fact that, within a social world which is built and rebuilt all the time, there is a cyclical process of thinking and acting according to the negotiated realities ${ }^{(7)}$. Such aspect can often legitimate the effectiveness of healthcare measures and the tuberculosis committee of that case study effectively reflects this process. As shown in the literature, there is no absolute power or domination, but constructive relational processes ${ }^{(4-7)}$.

The committee works pro-actively in the search for treatment solutions and tracking of new cases of the disease in the town. The partnership with NGOs which work with homeless people is an aspect of this proactivity (Figure 2). This aspect is in line with the fact that healthcare actions for the control and treatment of tuberculosis require the integrality of actions, ensured by a model of healthcare that considers the vulnerable nature of a treatment for such disease ${ }^{(17)}$. It is based on this understanding of the disease that the committee contributes with its control measures, seeking to promote access to diagnosis and treatment of the tuberculosis for more vulnerable populations.

The work of the civil society in the effective control of tuberculosis reflects a context in which the search for positive results, the performance of measures in the situational reality of the town management model and the process of governance should encompass feasible situations that provide a communication between civilians and the public healthcare service.

Based on the above, another line of analysis was developed and named Effective measures in Tuberculosis control. This line of analysis shows that positive results are concrete in so far as opportunities are open for discussions and development of measures that support community health. The control of transmissible diseases, including tuberculosis, finds these opportunities by having access to the civil society of the town, which is organized and works on issues concerning assistance to the people infected with tuberculosis, supervised treatment and prevention measures. In other words, it can be stated that the performance of the referred committee is effective in the reality of the healthcare model.

This is based on the assumption that the concept of effectiveness is built within an understanding of the uncontrolled reality of the event under study. To be effective is to achieve a result through an action that is appropriate to the reality and has a positive effect on the health of the population. From this understanding, the effectiveness is the ability of a program, or a model, or a healthcare measure, to achieve the proposed objectives under uncontrolled conditions ${ }^{(18)}$.

The management model of a town's public healthcare service needs to be well designed for a certain epidemiological/social reality and should work on implementing satisfactory strategies. It is also understood that the management models are effective when they structure real objectives in line with the real social needs, developing credible healthcare practices for those who are part of the organization and for its context or work environment ${ }^{(18)}$.

The understanding about the effective performance of the studied tuberculosis committee is based on a line of analysis that, when reflected in the inter-relationship among various actions, produces positive outcomes in the control of tuberculosis. Therefore: [...] yes, the participation of the organized civil society is effective [...] very much [...] it is effective but incipient and it could be more visible and bigger [...] has a positive outcome due to the different views of the different people there [...] so, what is interesting [...] it is interesting to articulate all these views for the control of tuberculosis [...] (Participant 6, member of an NGO for the control of infectious diseases).

From this perspective, the performance and development of an effective committee occurs through the joint action of several people, who develop a thinking reality about the event to be worked on ${ }^{(7)}$. The statement of a member of the committee who represents the non-governmental organizations shows the view that the effectiveness of a management model is developed with the joint participation of several people and institutions within their contextual realities $^{(7)}$. It is the dialogue among these people that permits the development of meanings for an effective and participatory management. 
In the town studied, the healthcare model, even being hegemonically hospital centered and focused on solving cases of urgency and emergency, in a sense also seeks to act based on a health surveillance model. It is believed that a town with a healthcare model that is also focused on health surveillance provides room for healthcare co-management to work on the surveillance of diseases like tuberculosis. In this scenario, the referred committee finds a field of organization of actions for the control and surveillance of tuberculosis in the studied town. Surveillance measures are essential to the town, which finds in the committee the support for the development and guidance of practices for the surveillance of tuberculosis and its comorbidities. Data collection, dissemination and information about the disease, evaluation of measures undertaken, as well as suggestions and recommendations of measures to control the disease are measures taken by the committee which meet the needs of a healthcare comanagement model.

In a management where members play an important role in decision making concerning healthcare measures, the different views that the various people have are directly related to the social and professional roles these people perform within the healthcare service ${ }^{(4)}$.

Tuberculosis control, through the committee, is shown to be effective and decisive for the development of the proposed healthcare measures. The discussion forum guides the measures and directs them into the reality of governance and sustainability of the local health department. In this context of governance, the mobilization of the society is shown as a potential that directly reflects the effectiveness of collective tuberculosis control(19).

The committee shows that dialogue promotes the development of solid measures in the control of the disease, such as directly observed treatment and active search for cases, as noted in the statement of a nurse who works in the SUS: [...] another thing that is bringing results [...] it is the meeting with other points of view [...] because when you are alone in here [...] the committee is actually related to the political direction [...] the direction of proposals [...] we also perform active searches [...] if this search is effective? [...] it is performed in the best possible way [...] I do not know but it does happen [...] the search is done [...] the treatment observed $[\ldots .$.$] the health education is performed [...] we provide guidance$ $[\ldots]$ we campaign $[\ldots]$ with staff $[\ldots]$ with convicts $[\ldots]$ this is done [...] (Participant 4, Nurse working in SUS).

For the committee, its relevance in healthcare service management is clear with a political direction, reflected in the development of proposals to guide effective measures to control the tuberculosis. Thus, it is understood that the inter-relationships among the members of the committee contribute to the active search for convicts and homeless people, highlighting the relevance of the referred committee for specific care measures. Based on this understanding, the active search for cases is essential for the control of tuberculosis, mainly concerning the relation of these measures with the practice of community health agents and social activities, as elucidated by the view of a member of the committee, a nurse working in SUS (participant 4).

The association between community health agents and social activities is shown to be necessary for the integration of different points of care of the town's healthcare service system, as well as for the flow of information obtained through the active search for cases $^{(20)}$. In this context of care, guided by the referred committee, the effectiveness of tuberculosis control moves alongside, guiding the healthcare measures focused on the search for Directly Observed Treatment/ DOTS by community health agents in various socially vulnerable populations, such as homeless people and convicts. The DOTS shows to be an essential procedure and an alternative access to the treatment, control and cure of tuberculosis ${ }^{(17-19)}$

By analyzing the referred committee, it is possible to understand that this is convergent with patient follow-up measures during treatment, and committed to the articulation of knowledge for the implementation of this measure within the town's management model. The support provided by the town to the social measures and the political debate was evident in the statement of a committee member (Participant 4). The relationship developed within the reality of articulation between the local health department and the service offered to tuberculosis patients is reflected in an association involving partnership and joint development ${ }^{(7-11)}$ and confirms the need for conversational and political spaces for decision making in order to achieve effective tuberculosis control.

The town's management model studied is, in a sense, going through a period of search for a management in which there is social participation, so that the assistance and health care can be more effective and produce positive results for the manager, the user and the professional working at the service ${ }^{(21)}$. Based on the understanding that the civil society participates in decision making concerning measures for tuberculosis 
control in the town under study, a line of analysis was developed: Association with the Management Model.

Despite some centralized management practices, the management of the town's healthcare system has been seeking healthy alternatives for the management issue in the control of infectious diseases. One of these alternatives is the hospital management adopted by some hospitals in the town, which opted for collective management and are witnessing positive results in their administration $^{(21)}$. In this process, it is believed that the management with the participation of a specific committee for the tuberculosis is shown to be a strong and decisive link for decision making concerning the healthcare area in the town. It is in this scenario that the participation of the tuberculosis committee starts, since it performs its duties within a perspective of transmission and development of healthcare system guidelines, working with projects and priorities of other management bodies and other areas with user participation(4-14).

Collective management, involving the participation of healthcare workers, occurs in some healthcare management entities and is shown to be effective and produces positive results for hospital care in the studied town ${ }^{(21)}$. It is noteworthy that a shared management model, when effective, deals with the decentralization of the service organization and involves the implementation of regional autonomy ${ }^{(14)}$.

The studied committee was formed based on a movement for the organization of tuberculosis care in the town and according to demands related to epidemiology, care and knowledge production about the development of the disease, as well as according to the social space offered by the local health department for discussions on the tuberculosis issue. The committee contributed to this process in the late 90's, through a group composed of professionals working in the service, faculty members and representatives of the local health department with the purpose of controlling the disease in the town. Initially, as a result of the common interest, in conjunction with the demands of the disease in the town, the group was formed as an informal committee. Since the beginning, the intention was that this would be an independent committee. With the emergence of the tuberculosis program in the town and the offer of a space for discussions and decision making concerning healthcare measures, the committee was structured as a formal component of the local health department, as mentioned in the statement of a member of the committee under analysis:
[...] good when it comes to people who get together, I understand civilian people who get together and this is reflected in our committee [...] it is our point of support and discussion [...] that [...] I do not feel alone when thinking about tuberculosis [...] we have a partnership with the local health department [...] we are going to the city council [...] (Participant 9, SUS user).

Healthcare professionals, including those who are organized to promote the participation of society in the control of infectious diseases, should incorporate to their work process measures related to the participation of the organized civil society, also internalizing the participation of the user in the local discussions for control of these diseases. In the studied town's management model, the community should be informed about what the disease is and how it is transmitted, and also about their co-responsibility in controlling the disease ${ }^{(8)}$.

Guided by the social constructionism perspective, the authors consider the possibility that the dialogue among various people underlies the development of knowledge about decision making, as well as the performance of measures that guide the clarification to the community about the aspects of the disease ${ }^{(7)}$. The tuberculosis committee of Ribeirao Preto/SP, analyzed from the social constructionism perspective on the development of measures and knowledge, is constituted as a link between the community, the healthcare service and department and seeks to act proactively, in order to maximize the performance of the community in relation to the healthcare services.

It is important to mention that, in Brazil, since the beginning of this century, the academic and governmental sectors have been receptive and available to strengthen partnerships based on increasing dialogue with the community(22).

Even with the commitment of the different government levels to incorporate community organization for the control of infectious diseases, this aspect is still initial for tuberculosis control(8). Therefore, one of the challenges faced by the Tuberculosis Committee, based on the participatory management model, is the need to improve the social control of the town: [...] a participation of the community to represent the tuberculosis in the council is necessary [...] so that it becomes more [...] more effective [...] a real leading role [...] that is what is expected [...] we will seek mechanisms for this to happen [...] (Participant 5, Healthcare professional, University Professor).

Among the many demands discussed, negotiated and developed by the committee, a line of concern is the 
search for the participation of the community to represent the disease in the city health council. The committee has an effective performance. This performance causes the community, which directly or indirectly experiences the disease, to get mobilized and seek representation to be part of the city health council.

Civil society may, depending on its empowerment, fulfill or not the duty to defend collective measures for the promotion of structural and health related changes(19). Therefore, managers should encourage social participation in healthcare co-management. The community organizations for tuberculosis have recently emerged, but the important role of this representation in the control of the disease should not be overlooked.

In comparison with the national social participation for tuberculosis control, the studied town has a lot of progress to make. However, the fact is that major advances in the representation of the society have already been incorporated into tuberculosis control.

\section{Conclusion}

This research developed knowledge that highlights the importance of a social group effectively organized to develop measures for tuberculosis control in a town where the members and committees participate in healthcare measures in relation to the control of Tuberculosis. The result of the research, outlined in this scientific article, can serve as an instrument of guidance for political measures and movements concerning the resolution of situations related to tuberculosis control in collective and participatory management models.

It is concluded that the participation of society is necessary to strengthen political practices in the healthcare area, defending collective interests and influencing social decisions. The case study presented permits the conclusion that such consideration about the social participation in tuberculosis control overtakes effective care measures for disease control in deliberative hard work, collectively developed within a management perspective in which the town provides the co-management space for a committee of people to fight for the health of the population.

The healthcare practices developed by the studied committee represent potentials to build innovative spaces and encourage the exercise of citizenship in the fight against tuberculosis. Thus, the relationships between users, service and management model should develop a process of incentive and mobilization, so that the health needs of people are represented in deliberative entities, such as a proactive tuberculosis committee.

\section{References}

1. Kapilashrami A, O'Brien O. The Global Fund and the re-configuration and re-emergence of civil society: Widening or closing the democratic deficit? Int J Res Pol Practice. 2012,7(5):1123-31.

2. Pfeiffer J, Chapman R. Anthropological Perspectives on Structural Adjustment and Public Health. Ann Rev Anthropol. 2010;39(1):149-65.

3. Cathal D, Preeti P. Civil society organizations and global health initiatives: Problems of legitimacy. Soc Sci Med. 2008,66(9):1928-38.

4. Cecilio LCO. Colegiados de gestão em serviços de saúde: um estudo empírico. Cad Saúde Pública. 2010,26(3):557-566.

5. Bulgarelli AF, Pinto IC, Palha PF, Figueiredo LA, Zacharias FCM, Villa TCS. Alliance between public health professionals and civil society on the tuberculosis control. Malaysian J Nurs. 2011,3(1):7-9.

6. Ventura MM. O Estudo de caso como modalidade de pesquisa. Rev. SOCERJ. 2007;20(5):383-6.

7. Gergen KJ. An invitation to social construction. 2nd. ed. Washington (DC): Sage; 2009. 510 p.

8. Curto M, Scatena LM, Andrade RLP, Palha PF, Assis EG, Scatolin BE, et al. Tuberculosis control: patient perception regarding orientation for the community and community participation. Rev. Latino-Am. Enfermagem. 2010;18(5):983-9.

9. Marshall MN. Sampling for qualitative research. Fam Pract. 1996;13(6):522-6.

10. Preti D. Análise de textos orais. 6aed. São Paulo: Humanitas; 2003. 270 p.

11. Spink MJP. Práticas discursivas e produção de sentidos no cotidiano, aproximações teóricas e metodológicas. 3aed. São Paulo: Cortez; 2004. 296 p.

12. Moreira CMM, Zandonade LE, Noia EL. Sintomáticos respiratórios nas unidades de atenção primária no Município de Vitória, Espírito Santo, Brasil. Cad Saúde Pública. 2010; 26(8):1619-26.

13. Guanaes C, Mattos, ATR, Contribuições do Movimento Construcionista Social para o Trabalho com Famílias na Estratégia Saúde da Família. Saúde Soc. 2011,20(4):1005-17.

14. Guizardi FL, Cavalcanti FOL. O conceito de cogestão em saúde: reflexões sobre a produção de democracia institucional. Physis. 2010,20(4):1245-65. 
15. Uplekar M, Pathania V, Raviglione M. Private practitioners and public health: weak links in tuberculosis control. Lancet. 2001;358:912-6.

16. Buse K, Tanaka S. Global Public-Private Health Partnerships: lessons learned from ten years of experience and evaluation. Int. Dent. J. 2011;61(2):2-10.

17. Arakawa T, Arcêncio RA, Scatolin BS, Scatena LM, Ruffino-Netto A, Villa TCS. Accessibility to tuberculosis treatment: assessment of health service performance. Rev. Latino-Am. Enfermagem. 2011;19(4):117-21.

18. Donabedian A. Explorations in quality assessment and monitoring. In: Brown LD. Quality assurance of health care in developing countries. The quality assurance project, center for human services. Washington (DC): Routledge; 1980. p. 45-62.

19. Newell J, Collins CD, Baral SC, Omar MA, Pande SB. Decentralization and TB control in Nepal: understanding the views of tuberculosis control staff. Health Policy. $2005 ;(73) 2: 212-27$.

20. Nogueira JA, Netto AR, Monroe AA, Gonzales RIC, Villa TCS. Busca ativa de sintomáticos respiratórios no controle da tuberculose na percepção do Agente Comunitário de Saúde. Rev Eletrônica Enferm. [periódico na Internet]; 2007; [acesso 07 dez 2012]; (9)1:106-18. Disponível em: http://www.fen.ufg.br/fen_revista/v9/ n1/pdf/v9n1a08.pdf

21. Bernardes A, Cecilio LCO, Évora YDM, Gabriel CS, Carvalho MB. Collective and decentralized management model in public hospitals: perspective of the nursing team. Rev. Latino-Am. Enfermagem. jul-ago 2001;19(4):1003-10.

22. Santos ET Filho, Gomes ZMS. Estratégias de controle da tuberculose no Brasil: articulação e participação da sociedade civil. Rev Saúde Pública. 2007; 41 suppl:111-6. 